\title{
Dependence of ${ }^{18} \mathrm{~F}$ Production Yield and Radioactive Impurities on Proton Irradiation Dose
}

\author{
Imam Kambali, ${ }^{1}$ Parwanto, ${ }^{1}$ Hari Suryanto, ${ }^{1}$ Nur Huda, ${ }^{2}$ Ferdi D. Listiawadi, \\ Herta Astarina, ${ }^{2}$ Ratu R. Ismuha, ${ }^{2}$ and Kardinah ${ }^{2}$ \\ ${ }^{1}$ Center for Radioisotope and Radiopharmaceutical Technology, National Nuclear Energy Agency (BATAN), Puspiptek Area, \\ Serpong, South Tangerang, Indonesia \\ ${ }^{2}$ Dharmais Cancer Hospital, Jakarta, Indonesia
}

Correspondence should be addressed to Imam Kambali; imamkey@batan.go.id

Received 25 February 2017; Revised 24 May 2017; Accepted 7 September 2017; Published 9 October 2017

Academic Editor: Leonardo Golubovic

Copyright (c) 2017 Imam Kambali et al. This is an open access article distributed under the Creative Commons Attribution License, which permits unrestricted use, distribution, and reproduction in any medium, provided the original work is properly cited.

\begin{abstract}
Radiation safety for patients during positron emission tomography (PET) procedures is affected by the amount of radioactive impurities generated during production of fluorine-18 $\left({ }^{18} \mathrm{~F}\right)$ radionuclide. In this investigation, the dependence of ${ }^{18} \mathrm{~F}$ production yield and radioactive impurities on proton irradiation dose is discussed. Enriched water $\left(\mathrm{H}_{2}{ }^{18} \mathrm{O}\right)$ target was bombarded perpendicularly by $11-\mathrm{MeV}$ proton beams at various proton doses. Experimental results indicated that the ${ }^{18} \mathrm{~F}$ radioactivity yield and the amount of ${ }^{56} \mathrm{Co}$ and ${ }^{110 \mathrm{~m}} \mathrm{Ag}$ radioactive impurities depend strongly on the proton dose. In the proton dose range between $2 \mu \mathrm{Ahr}$ and $20 \mu \mathrm{Ahr}$, the radioactive impurities increased with increasing proton dose. There was no significant difference in the radioactivity yield of both ${ }^{56} \mathrm{Co}$ and ${ }^{110 \mathrm{~m}} \mathrm{Ag}$ impurities at low proton dose between 2 and $10 \mu \mathrm{Ahr}$. However a huge difference was recorded when the dose was increased above $10 \mu \mathrm{Ahr}$. The experimental data can be used to predict the amount of impurities generated during ${ }^{18} \mathrm{~F}$ production at proton dose of higher than $20 \mu \mathrm{Ahr}$.
\end{abstract}

\section{Introduction}

Current nuclear methods in medical and industrial radioisotope production have been mostly involving nuclear reactors and circular accelerators. Subatomic particles such as neutron, proton, deuteron, ${ }^{3} \mathrm{He},{ }^{4} \mathrm{He}$, and other heavier particles are generated and then accelerated to certain energies sufficient for production of radioisotopes. At thermal energy, neutrons can be directed into a target to create radioisotopes relevant for nuclear medicine applications, such as ${ }^{154} \mathrm{Sm}$, ${ }^{166} \mathrm{Ho},{ }^{149} \mathrm{Pm},{ }^{166} \mathrm{Ho},{ }^{161} \mathrm{~Tb}$, and ${ }^{177} \mathrm{Lu}[1,2]$. Deuteron particles accelerated in circular accelerators or cyclotrons have been recently employed to produce short-lived medical radioisotopes such as ${ }^{44 \mathrm{~m}} \mathrm{Sc},{ }^{44 \mathrm{~g}} \mathrm{Sc},{ }^{155} \mathrm{~Tb}$, and ${ }^{161} \mathrm{~Tb}[3,4]$, whereas ${ }^{3} \mathrm{He}$ particles have been suggested for production of ${ }^{44 \mathrm{~m}, 46 \mathrm{~m}+\mathrm{g}, 47,48} \mathrm{Sc},{ }^{48} \mathrm{~V}$, and ${ }^{48} \mathrm{Cr}$ radioisotopes [5].

Proton beams generated from cyclotrons have been widely employed to produce radionuclides relevant for medical applications $[6-8]$ as well as materials studies $[9,10]$.
One of the most widely used radionuclides in medical diagnoses for positron emission tomography (PET) modality is fluorine-18 $\left({ }^{18} \mathrm{~F}\right)[11,12]$. Research on theoretical and experimental aspects of ${ }^{18} \mathrm{~F}$ production using small cyclotrons has been carried out elsewhere to study the optimum target system and irradiation parameters [13], radioactive by-products in the cyclotron vicinity [14], and identification of radioactive impurities [15].

The main parameters affecting the types of radionuclidic impurities found in the enriched water target during ${ }^{18} \mathrm{~F}$ production include the type of the window separating the cyclotron chamber and the target system. The most common materials used as the window are Havar and titanium (Ti) foils. Moreover, proton beam energy employed in the bombardment also influences the number of impurities that fell in the postirradiated target. Previous studies discovered that several radioactive impurities such as ${ }^{56} \mathrm{Co},{ }^{48} \mathrm{~V},{ }^{51} \mathrm{Cr},{ }^{52} \mathrm{Mn}$, ${ }^{54} \mathrm{Mn},{ }^{54} \mathrm{Co}$, and ${ }^{58} \mathrm{Co}$ were found to contaminate the enriched water target when proton beams passed through 
Havar windows [16]. For $\mathrm{Nb}$ window, the most significant impurities detected by Köhler et al. were ${ }^{89} \mathrm{Zr},{ }^{92 \mathrm{~m}} \mathrm{Nb},{ }^{93 \mathrm{~m}} \mathrm{Mo}$, ${ }^{95} \mathrm{Tc}$, and ${ }^{96} \mathrm{Tc}[15]$.

Most studies on the radionuclide impurities have concentrated on the identification of the impurities without further studying the effect of proton beam current on the amount of the impurities. In the present investigation, the dependence of proton beam dose on the radioactivity yields of ${ }^{18} \mathrm{~F}$ and the impurities is discussed. A medical cyclotron which accelerates $11-\mathrm{MeV}$ proton beams is used to produce ${ }^{18} \mathrm{~F}$ and, in this study, the impurity measurement is performed using a gamma spectroscopy system.

\section{Materials and Methods}

2.1. Irradiation. A $97 \%$ pure enriched water $\left(\mathrm{H}_{2}{ }^{18} \mathrm{O}\right)$, purchased from Cambridge Isotope Laboratories, Ltd., was set as the target for ${ }^{18} \mathrm{~F}$ radionuclide production. As much as $1.8 \mathrm{ml}$ enriched water target was placed in a target system consisting of a Havar window and silver body as described elsewhere [14]. An 11-MeV proton beam was directed into the enriched water target at variable proton doses, ranging from 2 to $20 \mu \mathrm{Ahr}$. The proton dose was varied by varying the irradiation time while keeping the proton beam at a constant current of $30 \mu \mathrm{A}$. Note that a new $\mathrm{H}_{2}{ }^{18} \mathrm{O}$ target was prepared for every irradiation, allowing it to be free of contaminations prior to the irradiation. The irradiation procedure was performed using a typical Eclipse 11 cyclotron located at the National Cancer Center (NCC), Dharmais Cancer Hospital in Jakarta, Indonesia, as shown earlier [14].

2.2. Impurity Analysis and Radioactivity Yield. A portable gamma ray spectroscopy system which has been described elsewhere $[14,17]$ was used to detect and quantify the radionuclidic impurities. The Amptek-USA made spectrometer included a pocket MCA (Type MCA8000A) with the serial number 2278. The pocket MCA was connected to a $\mathrm{NaI}(\mathrm{Tl})$ detector. The impurities were recognized from their gamma ray energies as well as half lives.

Theoretical calculations of the end of bombardment (EOB) yield of ${ }^{18} \mathrm{~F}$ radionuclide were performed using the widely used equation [18] and the calculated results were compared with the experimental data by taking into account the radioactivity decays. Moreover, a computerized program was developed [19] using Visual Basic Language. While the ${ }^{18} \mathrm{~F}$ radioactivity was relatively easy to predict using the developed program, the impurity yields were not theoretically calculated in this investigation due to complex irradiation parameters.

\section{Results and Discussion}

3.1. Radioactivity Yield of ${ }^{18} \mathrm{~F}$. The gamma ray spectrum of ${ }^{18} \mathrm{~F}$ observed at different integrated beam currents, ranging from $2 \mu \mathrm{Ahr}$ to $20 \mu \mathrm{Ahr}$, is shown in Figure 1 . The figure indicates that the gamma ray peak at $0.511 \mathrm{MeV}$ increases with increasing proton dose. The experimental radioactivity hikes proportionally with increasing integrated proton beam

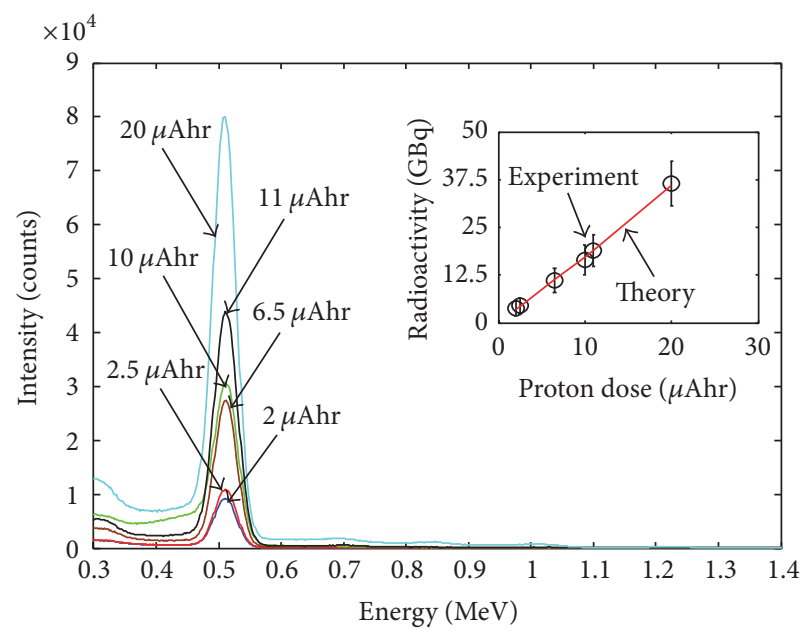

FIGURE 1: Recorded ${ }^{18} \mathrm{~F}$ spectrum at various proton doses observed 1 hour after the end of bombardment. The experimental radioactivity (circles) and calculated radioactivity (line) are shown in the inset.

TABLE 1: Production yield of ${ }^{18} \mathrm{~F}$ following 1-hour decay.

\begin{tabular}{lcc}
\hline \multirow{2}{*}{ Proton dose $(\mu \mathrm{Ahr})$} & \multicolumn{2}{c}{${ }^{18} \mathrm{~F}$ yield $(\mathrm{GBq})$} \\
\hline 2 & $3.81 \pm 0.37$ & Theory \\
2.5 & $4.42 \pm 0.40$ & 3.60 \\
6.5 & $11.01 \pm 0.64$ & 4.32 \\
10 & $16.52 \pm 0.78$ & 11.23 \\
11 & $18.87 \pm 0.84$ & 17.28 \\
20 & $36.53 \pm 1.16$ & 19.01 \\
\hline
\end{tabular}

current, which clearly agrees with the calculated radioactivity yield as seen in Figure 1 (inset).

At low proton dose of $2 \mu \mathrm{Ahr}$, the experimental radioactivity yield recorded in the gamma ray spectroscopy system is $3.8073 \pm 0.3737 \mathrm{GBq}$ as shown in Table 1 . The intensity trend follows linear line of $Y=1.81 X-0.50$ with $R^{2}=0.9961$ (in which $Y$ is the ${ }^{18} \mathrm{~F}$ radioactivity and $X$ is the proton dose). As the proton dose is increased to $20 \mu \mathrm{Ahr}$, the ${ }^{18} \mathrm{~F}$ radioactivity yield also goes up to $36.53 \pm 1.16 \mathrm{GBq}$. The linear regression equation derived in this experiment may be used to predict future ${ }^{18} \mathrm{~F}$ production when the proton beam is increased further above $20 \mu \mathrm{Ahr}$, presumably the proton energy is kept at $11 \mathrm{MeV}$, and the radioactivity is measured one hour after irradiation. For example, a proton dose of $50 \mu \mathrm{Ahr}$ is required to produce $85.10 \mathrm{GBq}$ of ${ }^{18} \mathrm{~F}$ radionuclide, whereas up to $107 \mu \mathrm{Ahr}$ proton dose is needed to obtain nearly $185.00 \mathrm{GBq}$ of ${ }^{18} \mathrm{~F}$.

In general, our experimental results agree with previous investigations by Nye et al. [20] and Wieland et al. [21], in which the radioactivity yield of ${ }^{18} \mathrm{~F}$ increases with increasing proton dose. For example, at proton dose of $3.34 \mu \mathrm{Ahr}$, our experiment results in ${ }^{18} \mathrm{~F}$ yield of $5.79 \mathrm{GBq}$ compared to 5.25 GBq by Wieland et al. [21]. 


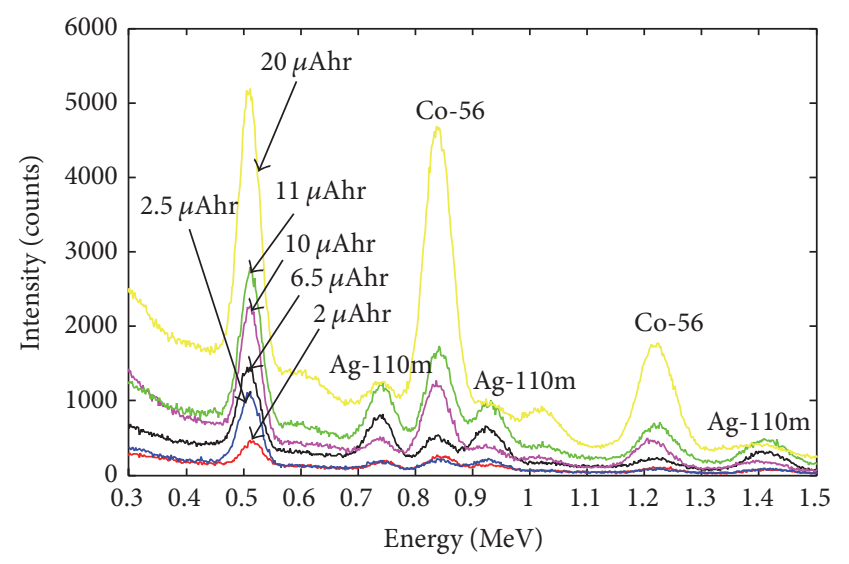

Figure 2: Gamma ray spectrum of ${ }^{56} \mathrm{Co}$ and ${ }^{110 \mathrm{~m}} \mathrm{Ag}$ impurities following 2 days of ${ }^{18} \mathrm{~F}$ decay period.

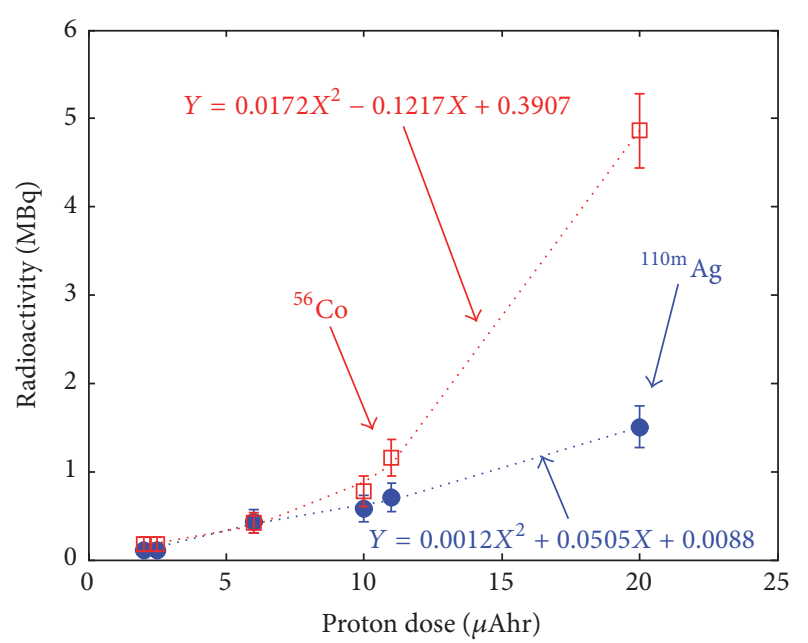

FIGURE 3: Radioactivity yield of ${ }^{56} \mathrm{Co}$ (unfilled squares) and ${ }^{110 \mathrm{~m}} \mathrm{Ag}$ (filled circles) following 2 days of decay period.

3.2. Experimental Spectrum and Yield of Radioactive Impurities. Following 2 days of cooling (decay) period, the majority of ${ }^{18} \mathrm{~F}$ radioactivity has decreased which allows better observing the gamma ray spectrum of radioactive impurities. As indicated in Figure 2, two radioisotopes are captured by the gamma ray spectroscopy system, namely, ${ }^{56} \mathrm{Co}$ and ${ }^{110 \mathrm{~m}} \mathrm{Ag}$. The two impurities have been previously discussed in the production of ${ }^{18} \mathrm{~F}$ radionuclide [16], despite no further discussion on the radioactivity dependence on the proton beam dose. The identified gamma rays for ${ }^{56} \mathrm{Co}$ are at $E \gamma=$ 0.847 and $1.238 \mathrm{MeV}$, whereas, for ${ }^{110 \mathrm{~m}} \mathrm{Ag}$, the strong peaks are recorded at $E \gamma=0.658,0.885$, and $1.4 \mathrm{MeV}$. In addition, the annihilation peaks at $0.511 \mathrm{MeV}$ originated from positron emissions of ${ }^{18} \mathrm{~F}$ radionuclide and gamma emissions of ${ }^{56} \mathrm{Co}$ and ${ }^{110 \mathrm{~m}} \mathrm{Ag}$ impurities with energies over $1.022 \mathrm{MeV}$ are also detected.

As can be seen in Figure 3, in general the radioactivity of both radioactive impurities $\left({ }^{56} \mathrm{Co}\right.$ and $\left.{ }^{110 \mathrm{~m}} \mathrm{Ag}\right)$ increases with increasing proton beam dose. For ${ }^{56} \mathrm{Co}$ impurity, the
TABLE 2: Radioactivity yield of ${ }^{56} \mathrm{Co}$ and ${ }^{110 \mathrm{~m}} \mathrm{Ag}$ impurities following 2 days of decay period.

\begin{tabular}{lcc}
\hline Proton dose $(\mu \mathrm{Ahr})$ & \multicolumn{2}{c}{ Impurity yield $(\mathrm{MBq})$} \\
& ${ }^{56} \mathrm{Co}$ & ${ }^{110 \mathrm{~m}} \mathrm{Ag}$ \\
\hline 2 & $0.18 \pm 0.08$ & $0.11 \pm 0.06$ \\
2.5 & $0.18 \pm 0.08$ & $0.11 \pm 0.07$ \\
6.5 & $0.42 \pm 0.12$ & $0.44 \pm 0.13$ \\
10 & $0.78 \pm 0.17$ & $0.58 \pm 0.15$ \\
11 & $1.16 \pm 0.21$ & $0.71 \pm 0.16$ \\
20 & $4.86 \pm 0.42$ & $1.51 \pm 0.24$ \\
\hline
\end{tabular}

radioactivity yield $(Y)$ matches empirical equation $Y=$ $0.0172 X^{2}-0.1217 X+0.3907$ (with $R^{2}=0.9978$ ), whereas the radioactivity yield of ${ }^{110 \mathrm{~m}} \mathrm{Ag}$ impurity follows equation $Y=$ $0.0012 X^{2}+0.0505 X+0.0088$ (with $R^{2}=0.9924$ ). Note that, in the equations, $X$ represents proton dose expressed in $\mu \mathrm{Ahr}$. Again, the equations may be applied to calculate the radioactivity yields of both ${ }^{56} \mathrm{Co}$ and ${ }^{110 \mathrm{~m}} \mathrm{Ag}$ impurities. For instance, using a $50-\mu \mathrm{Ahr}$ proton dose, the expected impurity yields for ${ }^{56} \mathrm{Co}$ and ${ }^{110 \mathrm{~m}} \mathrm{Ag}$ are nearly $37 \mathrm{MBq}$ and $5.55 \mathrm{MBq}$, respectively.

As shown in Figure 3 and Table 2, at low proton dose between 2 and $10 \mu \mathrm{Ahr}$, there is no significant difference in the radioactivity yield of both impurities. For instance at $2 \mu \mathrm{Ahr}$ proton dose, as much as $0.18 \pm 0.08 \mathrm{MBq}$ of ${ }^{56} \mathrm{Co}$ is detected, whereas $0.11 \pm 0.06 \mu \mathrm{Ci}$ of ${ }^{110 \mathrm{~m}} \mathrm{Ag}$ is recorded at the same proton dose. However the difference becomes more apparent and wider as the proton dose increases. At $20 \mu \mathrm{Ahr}$ proton dose, only $1.51 \pm 0.24 \mathrm{MBq}$ of ${ }^{110 \mathrm{~m}} \mathrm{Ag}$ is observed whereas around $4.86 \pm 0.42 \mathrm{MBq}$ of ${ }^{56} \mathrm{Co}$ is measured at the same proton beam dose, meaning that the amount of ${ }^{56} \mathrm{Co}$ impurity is more than 3 times that of the ${ }^{110 \mathrm{~m}} \mathrm{Ag}$.

The much higher increase in the ${ }^{56} \mathrm{Co}$ radioactivity yield observed in this experiment is most likely related to the following.

(1) Secondary Neutron Yield Production. During ${ }^{18} \mathrm{~F}$ production, secondary neutrons are generated via $(\mathrm{p}, \mathrm{n})$ nuclear reaction. While every incoming proton interacts with the atom it passes through, its interaction does not necessarily generate secondary neutrons. Thus the number of secondary neutrons produced in this process is not directly proportional to the number of the incoming protons. As discussed in previous studies $[14,16],{ }^{56} \mathrm{Co}$ is generated from ${ }^{56} \mathrm{Fe}(\mathrm{p}, \mathrm{n}){ }^{56} \mathrm{Co}$ nuclear reaction whereas ${ }^{110 \mathrm{~m}} \mathrm{Ag}$ is produced via ${ }^{109} \mathrm{Ag}(\mathrm{n}, \gamma){ }^{110 \mathrm{~m}} \mathrm{Ag}$ nuclear reaction. As a result, the number of ${ }^{110 \mathrm{~m}} \mathrm{Ag}$ radioisotopes is much less than that of ${ }^{56} \mathrm{Co}$ radionuclides.

(2) Silver Holder Geometry. While the Havar window used in this investigation is perpendicularly hit by the incoming proton beam, the silver body is parallel to the beam as discussed in previous studies [14]. Secondary neutrons generated by the $(\mathrm{p}, \mathrm{n})$ reactions are most likely to hit any materials perpendicular to the incoming proton beam as highlighted in earlier similar investigation [17]. As a result, it makes the 
TABLE 3: Ratio of ${ }^{56} \mathrm{Co}$ and ${ }^{110 \mathrm{~m}} \mathrm{Ag}$ impurities to ${ }^{18} \mathrm{~F}$ yield at EOB.

\begin{tabular}{lcc}
\hline Proton dose $(\mu \mathrm{Ahr})$ & \multicolumn{2}{c}{ Impurity-to- ${ }^{18} \mathrm{~F}$ yield ratio $(\%)$} \\
& ${ }^{56} \mathrm{Co}$ & ${ }^{110 \mathrm{~m}} \mathrm{Ag}$ \\
\hline 2 & $2.2 \pm 0.9$ & $1.2 \pm 0.8$ \\
2.5 & $1.9 \pm 0.9$ & $1.2 \pm 0.7$ \\
6.5 & $1.8 \pm 0.5$ & $1.4 \pm 0.5$ \\
10 & $2.2 \pm 0.5$ & $1.6 \pm 0.4$ \\
11 & $2.9 \pm 0.5$ & $1.8 \pm 0.4$ \\
20 & $6.2 \pm 0.5$ & $1.9 \pm 0.4$ \\
\hline
\end{tabular}

silver holder harder to be hit by the secondary neutrons and any recoiled atoms originated from the silver window. Thus the ${ }^{110 \mathrm{~m}} \mathrm{Ag}$ radioactivity yield detected in the water target is much lower than the ${ }^{56}$ Co yield.

3.3. Impurity-to $-{ }^{18} F$ Yield Ratio. Based on the experimental results as shown in Table 3, at the end of bombardment $(\mathrm{EOB})$, the average ratio between each impurity and ${ }^{18} \mathrm{~F}$ yield ranges between 1.2 and $6.2 \%$. For ${ }^{110 \mathrm{~m}} \mathrm{Ag}$ impurity, proton dose does not significantly influence the impurity-to${ }^{18} \mathrm{~F}$ yield ratio. In contrast, the proton dose has significant impact on ${ }^{56} \mathrm{Co}$ impurity-to- ${ }^{18} \mathrm{~F}$ yield ratio, particularly when the proton dose is increased above $10 \mu \mathrm{Ahr}$. In this case, the average on ${ }^{56} \mathrm{Co}$ impurity-to- ${ }^{18} \mathrm{~F}$ yield ratio jumps from $2.9 \%$ to $6.2 \%$. The difference in the impurity-to- ${ }^{18} \mathrm{~F}$ yield ratio between ${ }^{56} \mathrm{Co}$ and ${ }^{110 \mathrm{~m}} \mathrm{Ag}$ corresponds to both secondary neutron yield production and silver holder geometry as discussed in previous section.

\section{Conclusion}

Two radioactive impurities $\left({ }^{56} \mathrm{Co}\right.$ and $\left.{ }^{110 \mathrm{~m}} \mathrm{Ag}\right)$ found in the postirradiated water target following ${ }^{18} \mathrm{~F}$ production have been measured for their radioactivities. Experimental results indicate that the radioactivities depend strongly on the proton beam dose. The higher the proton dose the higher the radioactivities. At low proton dose of up to $10 \mu \mathrm{Ahr}$, there is no significant difference in the radioactivity of ${ }^{56} \mathrm{Co}$ and ${ }^{110 \mathrm{~m}} \mathrm{Ag}$ radionuclides. However the radioactivity difference becomes significant as the proton beam dose is increased above $10 \mu \mathrm{Ahr}$. At this point, ${ }^{56} \mathrm{Co}$ radioactivity is a lot higher than that of ${ }^{110 \mathrm{~m}} \mathrm{Ag}$, which is presumably due to secondary neutron yield production and silver holder geometry as discussed in the Results and Discussion.

\section{Conflicts of Interest}

The authors declare that they have no conflicts of interest.

\section{Acknowledgments}

This research project is supported by The World Academy of Sciences (TWAS) under the Principal Investigator's Research Grant no. 15-020 RG/PHYS/AS_I-FR3240287075, as well as the in-kind support from National Nuclear Energy Agency (BATAN) and Dharmais Cancer Hospital. Technical support by the cyclotron technicians and staff at Dharmais Cancer Hospital in Jakarta is also greatly acknowledged.

\section{References}

[1] L. Safavi-Tehrani, G. E. Miller, and M. Nilsson, "Production of high specific activity radiolanthanides for medical purposes using the UC Irvine TRIGA reactor," Journal of Radioanalytical and Nuclear Chemistry, vol. 303, no. 2, pp. 1099-1103, 2015.

[2] F. Monroy-Guzman, F. J. Barreiro, E. J. Salinas, and A. L. Treviño, "Radiolanthanides Device Production," World Journal of Nuclear Science and Technology, vol. 05, no. 02, pp. 111-119, 2015.

[3] C. Duchemin, A. Guertin, F. Haddad, N. Michel, and V. Métivier, "Production of scandium-44m and scandium-44g with deuterons on calcium-44: cross section measurements and production yield calculations," Physics in Medicine and Biology, vol. 60, no. 17, pp. 6847-6864, 2015.

[4] F. Szelecsényi, Z. Kovács, K. Nagatsu, M.-R. Zhang, and K. Suzuki, "Investigation of deuteron-induced reactions on natGd up to $30 \mathrm{MeV}$ : possibility of production of medically relevant $155 \mathrm{~Tb}$ and $161 \mathrm{~Tb}$ radioisotopes," Journal of Radioanalytical and Nuclear Chemistry, vol. 307, no. 3, pp. 1877-1881, 2016.

[5] F. Szelecsényi, Z. Kovács, K. Nagatsu, M.-R. Zhang, and K. Suzuki, "Production cross sections of radioisotopes from $3 \mathrm{He}-$ particle induced nuclear reactions on natural titanium," Applied Radiation and Isotopes, vol. 119, pp. 94-100, 2017.

[6] S. Rötering, K. Franke, J. Zessin et al., "Convenient recycling and reuse of bombarded $[18 \mathrm{O}] \mathrm{H} 2 \mathrm{O}$ for the production and the application of [18F]F-," Applied Radiation and Isotopes, vol. 101, pp. 44-52, 2015.

[7] C. Hoehr, E. Oehlke, F. Benard et al., "44gSc production using a water target on a $13 \mathrm{MeV}$ cyclotron," Nuclear Medicine and Biology, vol. 41, no. 5, pp. 401-406, 2014.

[8] P. Schaffer, F. Bénard, A. Bernstein et al., "Direct Production of ${ }^{99 m}$ Tc via ${ }^{100}$ Mo (p, 2n) on Small Medical Cyclotrons," Physics Procedia, vol. 66, pp. 383-395, 2015.

[9] I. Kambali and H. Suryanto, "Measurement of seawater flowinduced erosion rates for iron surfaces using thin layer activation technique," Journal of Engineering and Technological Sciences, vol. 48, no. 4, pp. 482-494, 2016.

[10] D. P. Singh, V. R. Sharma, A. Yadav et al., "Surface Wear Studies in Some Materials Using $\alpha$-induced Reactions," Journal of Nuclear Physics, Material Sciences, Radiation and Applications, vol. 1, no. 1, pp. 13-24, 2013.

[11] L. Wang, B. P. Lieberman, K. Ploessl, and H. F. Kung, "Synthesis and evaluation of $18 \mathrm{~F}$ labeled FET prodrugs for tumor imaging," Nuclear Medicine and Biology, vol. 41, no. 1, pp. 58-67, 2014.

[12] M. Gao, M. Wang, and Q.-H. Zheng, "Concise and highyield synthesis of T808 and T808P for radiosynthesis of [18F]T808, a PET tau tracer for Alzheimer's disease," Bioorganic and Medicinal Chemistry Letters, vol. 24, no. 1, pp. 254-257, 2014.

[13] E. Hess, G. Blessing, H. H. Coenen, and S. M. Qaim, "Improved target system for production of high purity [18F]fluorine via the $18 \mathrm{O}(\mathrm{p}, \mathrm{n}) 18 \mathrm{~F}$ reaction," Applied Radiation and Isotopes, vol. 52, no. 6, pp. 1431-1440, 2000.

[14] I. Kambali, H. Suryanto, and Parwanto, "Radioactive byproducts of a self-shielded cyclotron and the liquid target system for F-18 routine production," Australasian Physical and 
Engineering Sciences in Medicine, vol. 39, no. 2, pp. 403-412, 2016.

[15] M. Köhler, D. Degering, J. Zessin, F. Füchtner, and J. Konheiser, "Radionuclide impurities in [18F]F- and [18F]FDG for positron emission tomography," Applied Radiation and Isotopes, vol. 81, pp. 268-271, 2013.

[16] L. Bowden, L. León Vintró, P. I. Mitchell, R. G. O’Donnell, A. M. Seymour, and G. J. Duffy, "Radionuclide impurities in protonirradiated $[18 \mathrm{O}] \mathrm{H} 2 \mathrm{O}$ for the production of 18F-: Activities and distribution in the [18F]FDG synthesis process," Applied Radiation and Isotopes, vol. 67, no. 2, pp. 248-255, 2009.

[17] I. Kambali and H. Suryanto, "identification and angular distribution of residual radionuclides detected on the wall of BATAN's cyclotron cave," Atom Indonesia, vol. 42, no. 1, p. 1, 2016.

[18] I. Kambali, "Calculated radioactivity yields of Cu-64 from proton-bombarded Ni-64 targets using SRIM codes," Atom Indonesia, vol. 40, no. 3, pp. 129-134, 2014.

[19] H. Suryanto, F. A. Wibowo, and I. Kambali, "Software for ${ }^{18} \mathrm{~F}$ radionuclide yield calculation from enriched water target $\left(\mathrm{H}_{2}^{18} \mathrm{O}\right)$ irradiation using visual basic," in Prosiding Pertemuan dan Presentasi Ilmiah Teknologi Akselerator dan Applikasinya, vol. 16, pp. 56-61, Yogyakarta, Indonesia, October 2014.

[20] J. A. Nye, D. W. Dick, and R. J. Nickles, "Pushing the limits of an O-18 water target," in Proceedings of the Application of Accelerators in Research and Industry, vol. 2003, pp. 1098-1101, 2003.

[21] B. W. Wieland, G. T. Bida, H. C. Padgett, and G. O. Hendry, "Current status of CTI target systems for the production of PET radiochemicals," in Proceedings of the Third Workshop on Targetry and Target Chemistry, vol. 1989, pp. 34-48, 1989. 

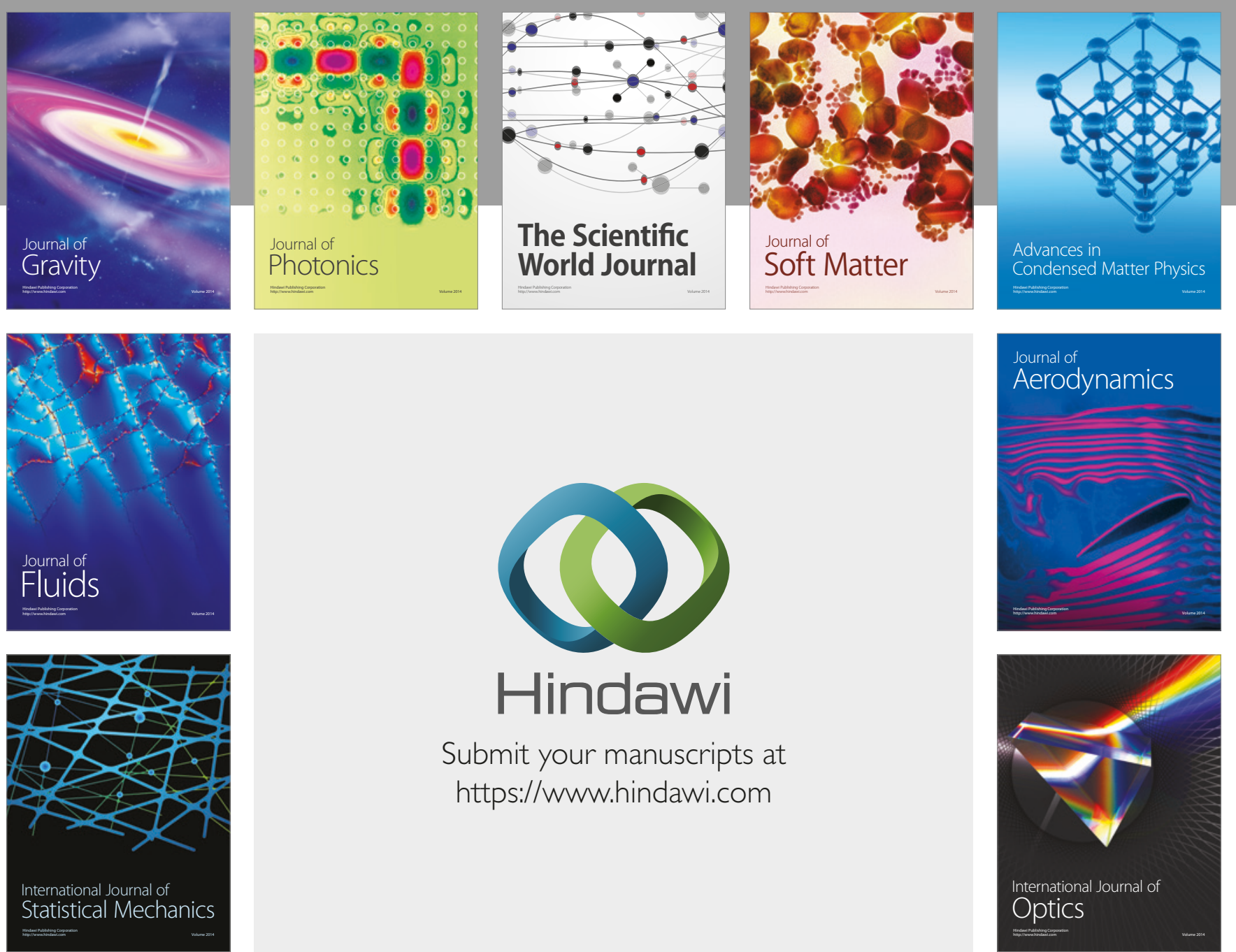

Submit your manuscripts at

https://www.hindawi.com
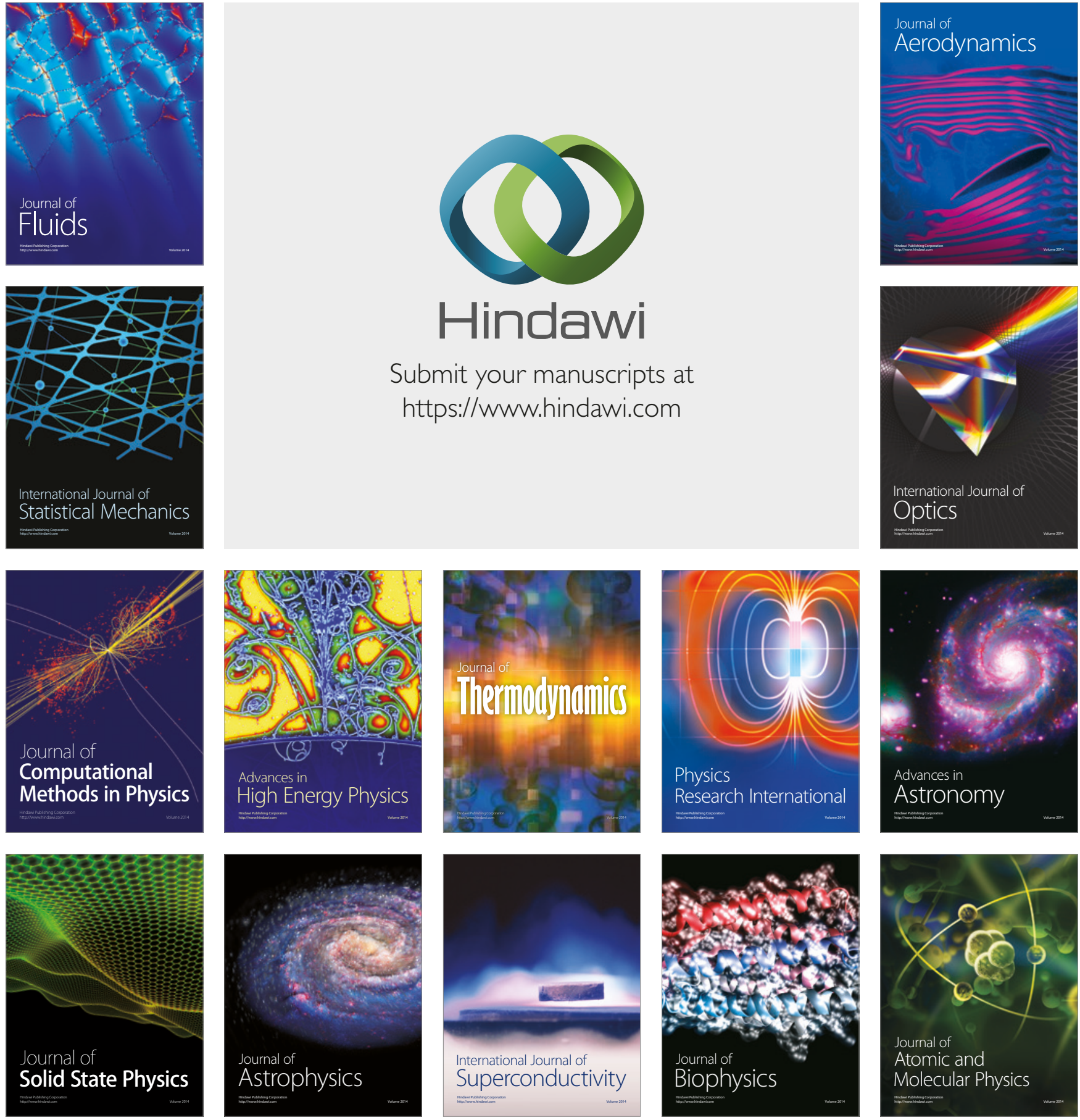